\title{
Comparing Canadian health care to that in other countries: looking beyond the headlines
}

\author{
Finlay A. McAlister MD MSc, Peter Cram MD MBA, Chaim M. Bell MD PhD
}

- Cite as: CMAJ 2018 February 26;190:E207-8. doi: 10.1503/cmaj.171527

$\mathbf{T}$ he latest Commonwealth Fund Report ranked Canada's health care system ninth out of 11 high-income countries. ${ }^{1}$ Its findings have been widely reported in the media. However, two other international comparisons, a comparison by the World Health Organization (WHO) on healthadjusted life expectancy (HALE) and the Global Burden of Disease study reach quite different conclusions about the relative quality of Canadian health care. ${ }^{2,3}$ What is the truth? We may find the answer by examining the data behind the headlines.

The Commonwealth Fund Report uses a combination of national-level administrative data (12 items) and surveys of patients and providers (59 items) to rank countries in each of five domains: care process, access, administrative efficiency, equity and health care outcomes. The domain rankings are then averaged to assign an overall ranking for each country. Careful perusal of the individual items used to create the scores shows some surprising insights.

For example, Canada's poor rankings in the domains of "access" and "equity" are largely driven by the costs of dental care and drugs, with $30 \%$ of Canadian respondents reporting difficulties in paying for drugs and $28 \%$ skipping routine dental care (compared with $12 \%$ and $11 \%$, respectively, in the United Kingdom, the country ranked highest in these domains). This highlights one of the key challenges in international comparisons: health system boundaries differ among countries, and although some (such as the UK) include dental care and drug coverage as universal benefits, Canada does not. ${ }^{4}$

Although Canada also ranked poorly in the "care process" domain, this appears to be driven by lack of electronic health records and clinical decision support in the primary care practices surveyed (28\% in Canada v. $81 \%$ in the UK). However, $92 \%$ of the Canadian physicians who were surveyed reported having necessary test results or medical records when seeing a patient compared with $94 \%$ of UK physicians, and patients reported that their physician had their key medical information $83 \%$ of the time in Canada versus $84 \%$ of the time in the UK. These survey items do not support the idea that relative lack of electronic health records truly compromises care in Canada, in particular, since Canada ranked highest in vaccination rates and mammography screening, and had the lowest rates of admissions to hospital for ambulatory care-sensitive conditions. Taken together

\section{KEY POINTS}

- Health care in Canada is ranked poorly relative to other highincome countries by the 2017 Commonwealth Fund Report.

- Both the health-adjusted life expectancy tables from the World Health Organization and the Healthcare Access and Quality Index from the Global Burden of Disease Study place Canada in the top $10 \%$ of countries, above several comparators that were included in the Commonwealth Fund Report.

- There are many potential reasons for discrepancies between different international rankings, including different definitions of health system boundaries, different sources of data, and different methodologies and limitations.

with accumulating evidence that electronic health record and decision support technology may not improve (and indeed may sometimes adversely affect) efficiency, communication or the satisfaction of patients or providers, ${ }^{5}$ we believe it reasonable to question whether access to such electronic resources should be a metric for measuring quality of health care.

Furthermore, we question whether the health care outcomes that the Commonwealth Fund focuses on are truly comparable across jurisdictions. For example, because the threshold for admission to hospital of patients with stroke varies widely among countries, ${ }^{6}$ the Commonwealth Fund's choice to focus on 30-day survival rates after hospital admission for ischemic stroke penalizes countries like Canada, where only the sickest patients are admitted to hospital. In fact, although Canada is ranked last in the Commonwealth Fund Report for stroke care while in hospital, Canada's total stroke mortality (considering all cases, not just the hospitalized cases) and disability-adjusted life-years lost to stroke per 100000 is among the lowest in the world, and lower than in the UK and United States. ${ }^{7,8}$

A similar problem arises with respect to infant mortality rates. Canada includes babies born before 24 weeks gestation and weighing less than $500 \mathrm{~g}$ as part of infant mortality data, whereas several European countries do not, ${ }^{9}$ resulting in high infant mortality rates for Canada. ${ }^{10}$

The Commonwealth Fund Report also ranks Canada low because it has one of the highest rates of reporting of two or more chronic diseases by adults aged 18-64 years. However, we 
believe that this item conflates "presence" of disease and "prevalence" of screening/reported diagnosis/patient awareness. Moreover, although Canadians with cardiovascular risk factors are more likely to be aware of their conditions compared with peers in the US or the UK, Canadians are also more likely to be receiving treatment and do exhibit higher control rates. ${ }^{7}$

In contrast to the Commonwealth Fund Report, the WHO ranks Canada among the top 10 of 191 countries and third among the 11 countries included in the Commonwealth Fund Report for HALE at 72.3 health-adjusted life-years (compared with 71.4 life-years in the UK and 69.1 life-years in the US). ${ }^{2}$ Although HALE incorporates both mortality and morbidity (by weighting years of life by health status in those years estimated using the Health Utilities Index), the accuracy and comparability of survey data from different countries on disease prevalence, severity and quality of life are uncertain. ${ }^{11}$

A recent analysis from the Global Burden of Disease Study showed that Canada was in the top $10 \%$ of the 195 countries that were compared on the Healthcare Access and Quality Index, ranking above several countries that scored higher in the Commonwealth Fund Report. ${ }^{3}$ The index uses data from the Global Burden of Disease Study to rank countries by cause-specific death rates in each country that are adjusted for factors that health care cannot directly influence, such as demographics, social determinants of health and environmental risk exposures (but not individual risk factor levels or behaviours). Countries with lower rates of death from 32 conditions defined as amenable to health care interventions are ranked higher in the Healthcare Access and Quality Index. ${ }^{12}$ However, it should be recognized that this index does not provide insight into conditions that cause substantial morbidity but not mortality, and for which health care can still improve quality of life (e.g., osteoarthritis, cataracts or mental health conditions). Furthermore, the list of amenable mortality diagnoses needs updating to include infectious conditions such as HIV or hepatitis $C$ that are now treatable. In addition, as with any study relying on data from death certificates, there is a substantial risk of misclassification bias for causes of death.

Oscar Wilde noted that "the truth is rarely pure and never simple," and this is surely the case when one country's health care system is benchmarked against others. It is disconcerting that three international comparisons reach very different conclusions about the quality of health care in Canada, particularly when the public and government may view these data without proper context. It is important to recognize the potential data limitations with all comparisons across national boundaries, and we advise readers to look beyond the headlines when presented with such comparisons in the future.

\section{References}

1. Schneider EC, Sarnak DO, Squires D, et al. Mirror, mirror 2017: international comparison reflects flaws and opportunities for better US health care. New York: Commonwealth Fund Report; 2017.

2. Healthy life expectancy (HALE) at birth. Geneva: World Health Organization; http://www.who.int/gho/mortality_burden_disease/life_tables/hale/en/ (accessed 2017 Nov. 30).

3. Global Burden of Disease 2015 Healthcare Access and Quality Collaborators. Healthcare access and quality index based on mortality from causes amenable to personal health care in 195 countries and territories, 1990-2015: a novel analysis from the Global Burden of Disease Study 2015. Lancet 2017;390:231-66.

4. Papanicolas I, Jha AK. Challenges in international comparison of health care systems. JAMA 2017;318:515-6.

5. Hingle S. Electronic health records: an unfulfilled promise and a call to action. Ann Intern Med 2016;165:818-19.

6. Busby J, Purdy S, Hollingworth W. A systematic review of the magnitude and cause of geographic variation in unplanned hospital admission rates and length of stay for ambulatory care sensitive conditions. BMC Health Serv Res 2015;15:324. doi: 10.1186/s12913-015-0964-3.

7. Joffres M, Falaschetti E, Gillespie C, et al. Hypertension prevalence, awareness, treatment, and control in national surveys from England, the USA, and Canada and correlation with stroke and ischemic heart disease mortality. BMJ Open 2013;3:e003423.

8. Kim AS, Johnston SC. Global variation in the relative burden of stroke and ischemic heart disease. Circulation 2011;124:314-23.

9. Infant mortality rates (indicator). Paris (France): Organisation for Economic Co-operation and Development; 2017. doi: 10.1787/83dea506-en. Available: https://data.oecd.org/healthstat/infant-mortality-rates.htm (accessed 2017 Nov. 30).

10. Joseph KS, Liu S, Rouleau J, et al.; Fetal and Infant Health Study Group of the Canadian Perinatal Surveillance System. Influence of definition based versus pragmatic birth registration on international comparisons of perinatal and infant mortality: population based retrospective study. BMJ 2012;344:e746.

11. Mathers CD, Murray CJL, Salomon JA. Methods for measuring healthy life expectancy. In: Murray CJL, Evans D, editors. Health systems performance assessment: debates, methods and empiricism. Geneva: World Health Organization; 2003: 437-71.

12. Nolte E, McKee E. Measuring the health of nations: How much is attributable to health care? An analysis of mortality amenable to medical care. BMJ 2003;327: 1129-32.
Competing interests: Peter Cram has received a research grant paid to his institution. Chaim Bell has received consultant fees from the Ontario Ministry of Health and Long-Term Care outside the submitted work. No other competing interests were declared.

This article has been peer reviewed.
Affiliations: Faculty of Medicine and Dentistry (McAlister), University of Alberta, Edmonton, Alta.; Department of Medicine (Cram, Bell), University of Toronto, Toronto, Ont.

Contributors: Finlay McAlister conceived the study and wrote the first draft. Peter Cram and Chaim Bell revised the drafts critically for important intellectual content. All of the authors gave final approval of the version to be published and agreed to be accountable for all aspects of the work.

Correspondence to: Finlay McAlister, Finlay. McAlister@ualberta.ca 